\title{
From the Editor-in-Chief
}

\author{
Kimon P. Valavanis ${ }^{1}$
}

Received: 10 June 2021 / Accepted: 10 June 2021 / Published online: 1 July 2021

(C) The Author(s), under exclusive licence to Springer Nature B.V. 2021

Dear Colleagues,

To begin with, it is a great honor and pleasure to announce to you that the Editorial Board is enhanced with new members who joined JINT effective July 1. We also thank wholeheartedly those who have served in the Editorial Board. It is the handling Editors' commitment to excellence and to review and publish top notch papers that makes JINT a respectable journal. We look forward to working hard or harder to serve you, the authors, and the readers.

Next, I bring to your attention recommendations made during our last Board Meeting with respect to recommending and/or organizing Special Issues (Topical Collections). The emerging areas that worth exploring and soliciting original contributions include: AI and Deep Learning; Ethical AI; Soft Robotics; Robot Skill Learning; Autonomy; Trustworthy Systems; Robotics in Education; Reliability in Intelligent Systems; Benchmarking in Robotic Systems; HRI; Virtual and Augmented Reality based Interfaces for Robots; Unmanned Aviation Regulations, Protocols and Legal Issues; Safety and Security of Robot Systems. This list is not exhaustive, but it offers a plethora of opportunities in a wide spectrum of areas.

We welcome your feedback and ideas. Reach out to us, we are here to help.

In the meantime, enjoy the issue.

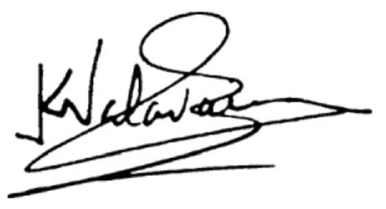

Kimon P. Valavanis

Editor-in-Chief

Publisher's Note Springer Nature remains neutral with regard to jurisdictional claims in published maps and institutional affiliations.

Kimon P. Valavanis

Kimon.Valavanis@du.edu

1 D. F. Ritchie School of Engineering and Computer Science, University of Denver, Denver, CO 80208, USA 